\title{
THEORETICAL ASPECTS OF INSTITUTIONAL SUPPORT FOR THE DEVELOPMENT OF AGRICULTURAL ENTERPRISES
}

\author{
Natalya Sirenko ${ }^{1}$, Inna Baryshevska ${ }^{2}$, Olha Melnik ${ }^{3}$ \\ ${ }^{1}$ Prof. Dr. Mykolayiv National Agrarian University, Georgiy Gongadze str. 9, 54020 Mykolayiv, Ukraine. Phone \\ +380962101045.E-mail: sirenko@mnau.edu.ua \\ ${ }^{2}$ Assoc. Prof. PhD (Economics) Mykolayiv National Agrarian University, Georgiy Gongadze str. 9, 54020 \\ Mykolayiv, Ukraine. Phone +380672819903. E-mail: inessa.83@ukr.net \\ ${ }^{3}$ Assoc. Prof. PhD (Economics) Mykolayiv National Agrarian University, Georgiy Gongadze str. 9, 54020 \\ Mykolayiv, Ukraine. Phone +380978547507. E-mail: melnykolga19@gmail.com
}

Received 1903 2020; Accepted 07122020

\begin{abstract}
The subject of the study is a set of theoretical and organizational principles of institutional support for the development of agricultural enterprises. Methodology. The methodological basis of the study consists of general methods of scientific knowledge of economic phenomena and processes. The realization of work tasks requires the following methods: theoretical method of generalization - while the study of scientific articles, laws and regulations; abstract logical method - generalization of theoretical and methodological provisions, as well as the definition of the objective of the study; method of system approach - definition of problems of institutional support for the development of agricultural enterprises. The objective of the study is to outline the institutional aspects of enterprise development, their classification, and the study of the importance of institutional transformations in the agricultural sector. Results. It was studied that the development of an enterprise is a rather complex concept, which is proposed to be understood as a long-term set of processes of quantitative and qualitative changes in the enterprise, which lead to improvement of its state by increasing the enterprise's potential, adapting to the external environment and internal integration, which helps to increase the company's ability to counteract negative influences of the environment and its viability. The development of the agricultural sector directly depends on the level of its institutional support, which is characterized by the number and efficiency of the institutions involved. According to the definition of institutions as the basic components of the institutional environment, it is analyzed that they are the factors of activating or inhibiting development, forming an effective or ineffective environment for the functioning of agents of the agricultural sector. It is determined that institutions act as a synergistic combination of opportunities and constraints in the development of the agricultural sector, structuring its relations, combining the system of factors, organizational components, processes and results of their actions; they represent a complex dialectical category.
\end{abstract} enterprises.

Keywords: institutes, institutional support, institutionalism, agricultural sector, development, agricultural

JEL Classification: B52, O11, O12, O43, D02.

\section{Introduction}

In modern conditions, the effective functioning of agricultural enterprises and the transition of the agrarian economy to the innovative way of development are possible as a result of integrated strategic management of agricultural production with a clear allocation of priorities of organizational, economic and innovative development.

Copyright (C) 2020. Published by Vytautas Magnus University. This is an open access article distributed under the terms of the Creative Commons Attribution Non-Commercial 4.0 (CC BY-NC 4.0) license, which permits unrestricted use, distribution, and reproduction in any medium provided the original author and source are credited. The material cannot be used for commercial purposes. 
At the same time, low rates of practical development of innovations and technical modernization in agriculture do not allow to overcome the considerable lag in innovative activity of agricultural sector of economy. An important factor in overcoming the serious contradictions in the agro-industrial production is the formation of a regional organizational and economic mechanism, technological modernization of agriculture, taking into account the peculiarities of the innovative development process. The relevance of the study is due to the discovery and the search for the most optimal conditions for the market, completely new approaches and forms of state regulation of the agricultural sector, taking into account the development of agricultural modernization, and is a theoretical and practical interest.

Works of many foreign scholars, among whom the writings of Nort (2000), Alimov (2005), Danylenko (2005), Prutska (2003), Sirenko (2005), Yakubenko (2005) et al. are devoted to the problems of the development of the economy from the point of view of institutionalism. The research of the studies conducted by these scientists shows that there are significant differences in the views and approaches to the classification of institutions (in the definitions of this concept). Despite the considerable number of publications on the above-mentioned topics and the depth of research by leading scholars on the problem of institutional support for enterprise development, as outlined above, the aspects of the concept of institutions remain unresolved.

The methodological basis of the study consists of general methods of scientific knowledge of economic phenomena and processes. The realization of work tasks requires the following methods: theoretical method of generalization - while the study of scientific articles, laws and regulations; abstract logical method - generalization of theoretical and methodological provisions, as well as the definition of the objective of the study; method of system approach - definition of problems of institutional support for the development of agricultural enterprises.

The purpose of the article is to outline the institutional aspects of enterprise development, their classification, as well as the study of the importance of institutional transformation in the agricultural sector.

\section{Results and discussion}

Development is the result of changes in people, objects and means of work. The criterion for these changes is the emergence of a new quality, which ensures the stability and harmonious functioning of the economic system or creates fundamentally new conditions for this. As a result, the conditions of operation change as well. According to Sirenko (2005), the factors of development are increase of labor productivity, increase of motivation of activity, application of new technologies, etc.

Korotkov (1997), considering development at the enterprise level, treats it as "... a set of changes that lead to the emergence of a new quality and strengthening the vitality of the system, its ability to resist the destructive forces of the environment". Zabrodskyi and Kyzym (2000) give a more extended definition of development, specifying it in relation to the economic-production system. According to their point of view, the development of economic and production systems is a process of transition of the economic and production system into a new, better-quality state by accumulation of quantitative potential, changes and complications of structure and composition, resulting in an increase in its ability to resist the destructive effects of the environment and efficiency of functioning.

We agree with the opinion of Pogorelov (2006) that the development of an enterprise is a rather complex concept, which is proposed to be understood as a long-term set of processes of quantitative and qualitative changes in the enterprise activity, which leads to improvement of its state by increasing the enterprise's capacity, adapting to the external environment and internal integration, which increases the ability of the enterprise to counteract the negative effects of the environment and its viability.

The development of the agricultural sector directly depends on the mechanism of creating the conditions of functioning, namely: the level of its institutional support, which is characterized by the number and efficiency of the institutions involved. Thus, the institutions are a priori in the 
development of the national economy and serve as a framework for directing the factors to ensure the optimal environment for the development of the agricultural sector.

Considering the problem of identifying institutions as the basic components of the institutional environment, we note that they are factors of activation or inhibition of development, forming an effective or ineffective environment for the functioning of agents of the agricultural sector.

Institutions are a synergetic combination of opportunities and constraints on the development of the agricultural sector, structuring its relations, combining the system of factors, organizational components, processes and the results of their actions; they represent a complex dialectic category. However, such a range of definitions of basic concepts of institutionalism does not necessarily lead to a clear interpretation of them without understanding the underlying foundations of institutions, which is the core of the truth of the understanding of the category, the definition of which will enable to adequately outline their role in certain spheres of management, in particular agricultural ones.

One of the founders of institutionalism is Nort (2000). Institutions, according to Nort's classification (2000), are divided into formal and informal. Formal institutions are legal entities and represent the entire legal basis of the economy, which forms the economic behavior of people. Of these, the most important are the institution of property rights, contract law, civil and criminal law, which determine the economic behavior of people. To formal institutions, he also includes political institutions, such as the constitution, laws governing civil and political rights. Much worse informal institutions are structured, under which Nort (2000) understands persistent habits, traditions, customs, in general, all that is called the culture of organization.

Some scholars have identified a specific core of institutions, which, in their opinion, most closely reflects its essence (Table 1).

Table 1. Approaches to the definition of "institution" in scientific literature

\begin{tabular}{|c|c|}
\hline Scientist & The essence of the concept \\
\hline Hrytsenko (2005) & $\begin{array}{l}\text { The upward category from which the institutions begin, is the category of "restriction". After } \\
\text { all, the restriction directs the activity to a certain direction and is a law for it. Restriction as an } \\
\text { upward category is manifested in the internal limitation of the cost of labor time, that is, in the } \\
\text { value that is being studied by labor theory, and in the external, quantitative limitations of } \\
\text { wealth, which is studied by marginalize, which testifies to the interpenetration of economic } \\
\text { theories }\end{array}$ \\
\hline Metelenko (2007) & $\begin{array}{l}\text { The starting point for the study of economic institutions is not the concept of activity or social } \\
\text { relations, but the concept of needs and interests. Thus, the emergence of economic institutions } \\
\text { has the nature of spontaneous self-organization, the basis of which is the division of labor, } \\
\text { caused by the divergence of the system of needs, interests and values of man as a doer }\end{array}$ \\
\hline $\begin{array}{l}\text { Matvieiev and } \\
\text { Liasota (2006) }\end{array}$ & $\begin{array}{l}\text { One of the main forming basic elements of economic institutions, are social norms of } \\
\text { behavior. Norms as informal restrictions of behavior stem from representations formed } \\
\text { individually on the basis of organized ideology and life experience. They play an extremely } \\
\text { important role in limiting the available alternatives to behavior, thus defining the course of } \\
\text { development of institutions }\end{array}$ \\
\hline Pustoviit (2006) & $\begin{array}{l}\text { A key factor for understanding institutions and the functioning of economic entities is the } \\
\text { rules that are defined as long-term permission or prohibition of entrepreneurial activity, } \\
\text { accompanied by real or symbolic sanctions or rewards that forms institutional constraints }\end{array}$ \\
\hline Yaremenka (2005) & $\begin{array}{l}\text { The institution arises not only as a way of repeating actions, but also as a way to reconcile } \\
\text { various interests and goals of interacting doers. The basis of the maturing of the conciliatory } \\
\text { appointment of institutions is the triad "contact - conflict - contract". The institutional } \\
\text { mechanism is designed to minimize the conditions for the emergence of conflicts }\end{array}$ \\
\hline Yakubenko, (2005) & $\begin{array}{l}\text { Focuses on four its features, which form the completed circle in his definition. Firstly, the use } \\
\text { of the notion of "institution" indirectly relies on a logical procedure for the removal of micro- } \\
\text { phenomena and processes at the macro level. The institution is always considered as the result } \\
\text { of socialization, public recognition. Secondly, the notion of "institution" is associated with the } \\
\text { organizational or legal design of the secured legitimacy of phenomena. Thirdly, and in the } \\
\text { economic aspect, this is the main thing, any institution is a sphere, or rather, a framework of } \\
\text { existence and the basis for obtaining specific forms of income. Fourthly, in any institution, } \\
\text { the sign of sociality is dominant, but not devoid of natural, psycho-biological foundations }\end{array}$ \\
\hline
\end{tabular}


Summarizing these approaches, we can identify agricultural institutions as relatively stable combinations of factors that regulate the economic behavior of doers in the agricultural sector and result from a compromise between their interests. The economic essence of agricultural institutions as elements of a single mechanism of influence on agricultural relations manifests itself in their functions.

Thus, agricultural institutions perform according to Lopatynskyi and Kyfiak (2014):

1) a stabilization function that manifests itself in the conjunction of constraints that form the institutions that holds back the transformational changes of certain economic structures and procedures. This function is provided by a system of interaction between formal and informal institutions, the closeness of which often constrains the change of formulas, or makes certain changes unacceptable. Of course, changes in institutional conditions are a tireless process, but the significance is the gradual transformation;

2) a function of reducing uncertainty - is carried out by establishing stable hierarchical status and structure of relationships;

3) a regulatory function - institutions determine one or another behavior of subjects by creating favorable or unfavorable conditions for it;

4) a system-forming function - institutions act as a criterion for the formation of certain sectoral formations.

Specifying the role of institutions in the mechanism of influence on the development of agricultural relations is manifested in the following:

- institutions are motivating and / or inhibiting factors of agricultural relations, which direct the behavior of subjects of the market sphere in a certain direction: affect the investment climate of the sector, the development and implementation of organizational and technological innovations, form the level of trust of subjects, both to each other, and to external counterparties;

- institutions, on the one hand, initiate a conflict of interests of the subjects of the agricultural sector, and on the other hand, are the result of the resolution of disputes. Moreover, in the first and second cases, they are impulses for the development of agricultural business entity and agricultural relations;

- due to their conservative nature, institutions act as protective elements against rapidly changing market conditions;

- institutions contribute to the social distribution of resources among participants in agricultural relations.

Based on Lopatynskyi's and Kyfiak's research (2014), in order to characterize the institutional environment, we will outline its main elements by class, type and form (Table 2).

Table 2. Elements of institutions in the institutional mechanism of development of the agricultural sector

\begin{tabular}{|l|l|}
\hline \multicolumn{1}{|c|}{ Elements } & \multicolumn{1}{c|}{ Specifications } \\
\hline Classes of institutions & $\begin{array}{l}\text { Regulatory support and its components; } \\
\text { The economic system and the conditions imposed by it; } \\
\text { Social mechanisms of influence. }\end{array}$ \\
\hline Types of institutions & $\begin{array}{l}\text { Basic: power-organizational, property, labor relations, pricing, contracting; } \\
\text { Derivatives: entrepreneurship, competition, infrastructure, mentally-ideological. }\end{array}$ \\
\hline Forms of institutions & $\begin{array}{l}\text { Formal: laws and regulations, established hierarchical interrelations, mechanisms for ensuring } \\
\text { compliance with established norms and rules; } \\
\text { Informal: traditions and customs, mentality, ideological guides. }\end{array}$ \\
\hline
\end{tabular}

Methods of classification of institutions by Lemeshchenko (2017) can be grouped into three large groups:

1. Institutes by the level of formality;

2. Institutes by branches (spheres) of activity;

3. Institutes by different levels of the hierarchy. 
Institutes by the level of formality are divided into formal, informal and mixed. social.

Institutes by branches (spheres) of activity are divided into economic, political, legal and

Economic institutions include rules defining the processes of production, distribution, exchange and consumption of goods and services produced.

Political institutions determine the type of political and electoral system, measures of political stability, the relation between the opposition and the government, and so on.

Legal institutions determine the legality, type of legal system, property relations.

Social institutions include rules for access to health and education, social protection measures, affect the gender balance and regulate the overall relationship between business entities. According to Lemeshchenko (2017), institutes by different levels of the hierarchy.

Institutional changes in Ukraine depend on changes in the format of relations between government and society. According to scientists Alimov, Danylenko and Trehobchuk (2005), there are three directions (models) of such relations in connection with economic development:

1) an autonomous government (independent in its actions against the preferences of groups of influence and voters);

2) a consensus of political decision-makers and groups of influence ("elite consensus"), which provides pressure groups with political support in exchange for pursuing an economic policy advantageous to them;

3) a consensus of political decision-makers and voters, which is characterized by the orientation of politicians to requests and preferences of the majority of the electorate.

\section{Conclusions}

Institutional changes as an integral part of economic modernization processes are conditioned by the need to form and consolidate such rules and norms of behavior and interaction in society, the observance of which leads to stimulating the activity of subjects of economic, scientific, educational and other activities in the development and implementation of advanced technologies, equipment, organizational and other innovations.

The institutional capacities of state and regional governments consist in managing the innovative development of the economy through the creation of effective institutions that regulate the innovation processes in the regions. This makes it possible to solve the priority tasks of modernizing the economy, increasing its efficiency and competitiveness, and creating a favorable institutional environment for the development of innovation activities.

The main goal of institutional changes in the agro-industrial sector of the economy is to increase the efficiency of agricultural production. Changes in property relations and the further transformation of economic relations, the economic mechanism and the social structure of the agricultural sector of the economy should provide conditions for a more dynamic development of the agro-industrial complex as a whole. The realization of this goal will lead to the formation of a developed market infrastructure, competitiveness of business entities, support for participants' profitability with an equivalent exchange between agriculture and related industries.

Prospects for further research are areas of improving the institutional support for financing the development of agricultural enterprises.

\section{References}

Alimov, O., Danylenko, A. and Trehobchuk V. (2005). Economic Development of Ukraine: Institutional and Resource Support // Joint Institute of Economics of the National Academy of Sciences of Ukraine. 520 p.

Korotkov, E. (1997). Management Concept. - Moskva: Deka. 304 p.

Lemeshchenko, N. (2017). Institutional Aspects of Enterprise Development. // International Journal “Internauka”. Series: "Economic Sciences. Vol. 3. p. 63-68. 
Lopatynskyi, Y. and Kyfiak, V. (2014). Development of the Agricultural Sector of National Economy on an Institutional Basis. Chernivtsi National University. 248 p.

Materials of the Scientific Symposium (2005). Institutional Architectonics and Mechanisms of Economic Development. Kharkiv National University named after V. N. Karazin; National Academy of Sciences of Ukraine. 298 p.

Matvieiev, S. and Liasota, L. (2006). Economic Sociology. - http://tourlib.net/books_others/matveev.htm [2019.12.02]

Metelenko, N. (2007). Enterprise as an Institution of National Economy in Terms of System Positions. // Economic Bulletin of the National Mining University. Vol. 1. pp. 32-39.

Nort, D. (2000). Institutions, institutional change and functioning of economy. - Kyiv: Osnovy. 200 p.

$75-81$.

Pogorelov, Yu. (2006). Enterprise development: concepts and types // Culture of the Black Sea peoples. Vol. 88:

Prutska, O. (2003). Institutionalism and Problems of Economic Conduct in a Transition Economy: monograph. - Kyiv: Lohos. 256 p.

Pustoviit, R. (2006). Formation of Institutional Environment of Entrepreneurship in the Transformational Economy: abstract for the degree of Doctor of Economics: specialty 08.01.01 // Economic Theory - Kyiv. 36 p.

Sirenko, N. (2005). Organizational and Economic Mechanism of the Anti-crisis Development of Agricultural Enterprises of the Region: abstract for the degree of Doctor of Economics: specialty 08.06.01 // Economy, Organization and Management of Enterprises. - Kyiv. 21 p.

Veblen, T. (1984). Theory of the leisure class. - Moskva: Prohress. 368 p.

Yakubenko, V. (2005). Fundamental Institutions in the Transformation Economy: the author's abstract for the degree of Doctor of Economics: specialty 08.01.01 // Economic Theory. Kyiv. 40 p.

Zabrodskyi, V., Kyzym, N. (2000). Development of Large-Scale Production Systems // Business Inform. 72 p. 